\title{
Coffee as an antidote to knowledge stickiness
}

\author{
Dr. Deborah Blackman \\ University of Canberra, Australia \\ Diane Phillips \\ Australian International Hotel School
}

\begin{abstract}
This paper considers the role of space in overcoming knowledge stickiness discussing space as both a location and a gap between other things. Qualitative case data indicates that there are three areas of space that need to be considered; physical, mental and virtual, as well as a range of reasons why space alone is not enough to support knowledge creation and learning. We argue that recognising these areas and developing them in a managed way may overcome inherent organisational learning and knowledge creation barriers.
\end{abstract}

\section{Introduction}

It is increasingly accepted that learning needs appropriate 'space' for it to occur effectively (Kets de Vries and Korotov, 2007; Edenius and Yakhlef, 2007; Guldberg and Pilkington, 2006). This space can be virtual or real and its role is to enable dialogue, interaction and collaboration; it is important, as the new knowledge desired from the learning develops in a processual (Newell et al., 2002), constructed (Elkjaer, 1999) and emergent way (Nonaka and Konno, 1998; Cook and Brown, 1999). McPherson and Nunes (2004) support this need for space, but highlight that the types of space matter and that face-to-face encounters are more likely to lead to greater knowledge development and transfer.

Knowledge creation, it is argued, is complex, messy and unpredictable, because any new knowledge emerges as a result of complex, cultural and interactive processes (Carlile, and Rebentisch, 2003; Firestone and McElroy, 2004; Hutchinson, 2006; Tsoukas and Vladimirou, 2001), and in terms of the 'stickiness' of knowledge transfer (Jensen and Szulanski, 2004). Consequently, how organisations manage learning spaces and places will affect their ability to overcome the knowledge and situational characteristics (Szulanski, 1995) which lead to stickiness and inhibit innovation of the organisation.

This paper will consider the need for appropriate space as a learning resource in order to enable knowledge creation. Initially the relationships between space, learning and knowledge will be discussed, developing a theoretical perspective that outlines the role of space and the types required fro effective organisational learning; the role of space in enabling knowledge 'stickiness' will be discussed in terms of how it can theoretically overcome transfer barriers.

\section{Organisational Learning, Knowledge Management and the need for Space}

Argyris and Schon (1996) state that learning is organisational when the learning that results from organisational inquiry has become embedded into either the mental models and images of the organisation held in its members' minds, or into the epistemological symbols, processes, procedures and physical manifestations of culture embedded in the organisational environment. How this embedding occurs is seen to differ greatly throughout the literature. Easterby-Smith, undertaking an overview of the organisational learning literature in 1997, identified six discrete disciplines each with its own definitions and features: 'psychology and O[rganisational] D[evelopment]', 'management science', 'sociology and organisational theory', 'strategy', 'production management' and 'cultural anthropology'. A study of these disciplines indicates that the outputs of organisational learning will be dependent, at least in part, upon how the organisation is viewed by its members (Easterby-Smith et al., 1998).

If the organisation is considered by its members as a system, then it follows that the focus of inquiry into organisational learning will be around channels and flows of information, the way that feedback processes operate in order to enhance the system and the transfer of individual learning to the organisation (indicating the 'management science', 'strategy', and 'psychology and OD' disciplines). On the other hand, if the organisation is regarded as something that is 
continually creating meaning and identity for itself in an evolutionary and holistic way, then it follows that the focus of inquiry will be on how meaning is created, communicated and imposed (indicating the 'cultural anthropology' and 'sociology and organisation theory' disciplines).

In some ways these two perspectives resonate with the notions of commodification versus relational perspectives of knowledge. Thus, the people setting up the systems will, inevitably, affect the way that the organisational learning is developed and supported. That there is a relationship between organisational learning and knowledge management becomes clear when a review of some definitions is undertaken. For example:

"Organizational learning is defined as the process within the organization by which knowledge about action-outcome relationships and the effect of the environment on these relationships is developed" (Duncan and Weiss, 1979 in Prange, 1999, p.29)

"Organizational learning means the process of improving actions through better knowledge and understanding" (Fiol and Lyles, 1985 in Prange, 1999, p.29)

Organisational Learning is the set of processes that are needed in order to develop and acquire knowledge. The tasks of developing and acquiring knowledge cannot be separated; what actually needs to be managed is the whole learning process. Unless learning is managed, the knowledge output created may be useless (McElroy,1999, 2000). Roth et al. (1994) stress that learning and knowledge must be linked with the core business, arguing that organisations need to understand how core knowledge drives their business and how to develop the skills to acquire, organise, codify and deploy knowledge (figure 1). They provide seven principles:

\begin{tabular}{|c|}
\hline A learning philosophy \\
\hline Improved rates of learning \\
\hline Adoption of 'stretch goals' \\
\hline 'Safe-failing' \\
\hline Systems for encouraging knowledge and learning \\
\hline Stimulating core knowledge processes \\
\hline Systems that cross functional boundaries. \\
\hline
\end{tabular}

Figure 1: Principles linking Knowledge, Learning and Strategy Roth et al., (1994)

These would support the acquisition of new ideas, ensuring that not only is learning encouraged and knowledge created, but also that such learning and knowledge is harnessed for the future. What can be seen in this table is that some of these principles will need to have space and transfer potential if there is to be learning and knowledge creation. The need for space is accepted (Edenius and Yakhlef, 2007), however, it is important to consider two issues: what is meant by space and why space is needed.

What is space

In its simplest form a space is an area provided for a particular purpose. In the case of learning and knowledge creation, therefore, it can be seen to be somewhere or something that will provide sufficient freedom from current constraints that will enable an individual to explore or develop new ideas; it is important that it provides the space even if that is not what it was originally designed for (Soloman et al., 2006). Space can also be seen to be a period of time or an opportunity for time for oneself. All these ideas imply another definition given which is that:

"Space is an interval between any two or more objects; an interval between two points in time" (BrainyMedia, 2008). 
This in-between role is an interesting one and leads to the question of whether the importance is the existence of a space between two things and, if so, is the interaction needed for learning occurring within, or beside, the space.

Why is space needed? Collaboration, interaction, knowledge transfer \& learning

There is some research interest now in the role of physical space in enabling and mediating, largely about the provision of opportunities for interaction. For example Cook and Brown (1999) when discussing the relationships between 'knowledge' and 'knowing', demonstrate that for new knowledge creation, knowledge needs to be moved from one format to another. In terms of space this is about where there as a space between two of the knowledge forms that can be accessed and then crossed to develop something new. The importance is that a space emerges for the interaction which can mediate between the knowledge forms. Similarly, Carlile and Rebentisch (2003) imply a need for a knowledge creation 'space' when discussing their transformation cycle: there will need to be space for storage in both physical and mental repositories. There will also need to be mental space in terms of the capacities to understand across different systems and create bridges between them:

"The iterative efforts between search and assessment can be described as two overlapping spaces. The first is the domain of knowledge sources that might eventually provide the solution - the search space. This search space evolves in scope or breadth over time as additional knowledge suggests new avenues of inquiry or the closure of others. Evolving from this search space is a set of possible solutions - the solution space." (Carlile and Rebentisch, 2003, p.1189).

The relationship between the two domains will determine the relevance, range and scope of the knowledge created. In terms of the definitions of space there will be an area for the creation of knowledge as well as a space between the searches and the solutions that enables those creating knowledge to make relevant decisions in terms of future transformations. Thus it can be seen that neither organisational learning, nor knowledge creation processes are in themselves sufficient in terms of effective knowledge creation; there needs to be some form of space for them to function. It could be argued that it is a lack of attention to the spaces required that leads to a lack of effective knowledge creation, acquisition or utilisation. In particular, it may be that the problems of knowledge stickiness might be caused or ameliorated, at least in part, by understanding and managing the spaces needed.

\section{Knowledge Stickiness and the Role of Space}

Knowledge stickiness is “the difficulty to transfer knowledge' (Szulanski, 1995, 2000).

"In any particular instance, the stickiness of a unit of information is defined as the incremental expenditure required to transfer that unit of information to a specified location in a form usable by a specified information seeker. When this expenditure is low, information stickiness is low; when it is high, stickiness is high" (von Hippel 1994)

In this description it can be seen that the transfer of knowledge is likened to communication in that there are various potential barriers between the 'sender' and the 'recipient' of knowledge as there are in the transmission of a message (Robbins, 2000). According to Szulanski, (2000) the characteristics of the knowledge and the situation combine to develop a range of factors which can prevent, or at least deter, knowledge transfer, see table 1.

\begin{tabular}{|l|l|}
\hline \multicolumn{1}{|c|}{ Stickiness Predictor } & \multicolumn{1}{c|}{ Description of the Predictor } \\
\hline Causal Ambiguity & $\begin{array}{l}\text { How clearly given ideas and work practices are. How } \\
\text { well understood is the relationship between a given } \\
\text { action and the given results }\end{array}$ \\
\hline Unproven Knowledge & $\begin{array}{l}\text { How solid is the proof that something is useful to an } \\
\text { organisation }\end{array}$ \\
\hline Source Lacks Motivation & $\begin{array}{l}\text { How clearly does the knowledge source see the } \\
\text { benefit in transferring some form of knowledge }\end{array}$ \\
\hline Source is not Perceived as Reliable & Whether the source was seen to have another \\
\hline
\end{tabular}




\begin{tabular}{|l|l|}
\hline Recipient Lacks Motivation & agenda, be traditionally unreliable etc. \\
\hline Recipient Lacks Absorptive Capacity & $\begin{array}{l}\text { How clearly does the knowledge recipient see the } \\
\text { benefit in receiving some form of knowledge }\end{array}$ \\
\hline Recipient Lacks Retentive Capacity & $\begin{array}{l}\text { Whether the recipient possessed the language, } \\
\text { extant knowledge, readiness, or skills to be able to } \\
\text { implement the potential transfer }\end{array}$ \\
\hline Barren Organisational Context & $\begin{array}{l}\text { Are there systems in place to encourage retention or } \\
\text { enable immediate practice that will support memory; } \\
\text { is the recipient simply too busy to be able to retain the } \\
\text { new ideas }\end{array}$ \\
\hline Arduous Relationship & $\begin{array}{l}\text { What is present within the organisational context to } \\
\text { encourage anyone to send or receive new ideas }\end{array}$ \\
\hline Table 1: Predictors of Stickiness & $\begin{array}{l}\text { Is communicating between the source and the } \\
\text { recipient easy or not }\end{array}$ \\
\hline
\end{tabular}

Not all of these will exist at every stage if knowledge creation and transfer and, consequently, not all can be improved or mediated by space, but it can be argued that some could be by providing the option for interactions to occur that will change the current mind set of at least one of those involved in the knowledge transfer. Factors that may be ameliorated might include: recipient lacks absorptive capacity; arduous relationship; barren organisational context and recipient lacks motivation

An example of where space can overcome potential stickiness is the creation of a community of practice (Guldberg and Pilkington, 2006). The argument is made that shared discourse and common notions of what is meant by good practice encourage learning by creating a 'safe interaction space'. In terms of the predictors of stickiness the organisational context becomes meaningful, the sources of knowledge are seen to be reliable and relationships become easy. Soloman et al. (2006) also argue that a crucial element in encouraging learning and, therefore, knowledge creation is the intersection between different spaces: in their case the social and work spaces. What is interesting is their idea of the 'in-between' (Soloman et al., 2006, 11); the space is something that bridges other ideas - in their terms, the identities of those involved. What is evident is that, whatever the space was, it enabled novelty and sharing to emerge. It overcame limitations that emerged through over formalisation and enabled causal ambiguity to remain whilst still utilising knowledge that could be seen to be of benefit. Moreover, it increased motivation by all parties.

\section{Methodology}

The subject of this research and its epistemological underpinnings align it with a qualitative approach because the focus is upon exploration and the development of new insights (Creswell 2003; Strauss and Corbin 1998 ; Leedy and Ormrod, 2005; Creswell, 1994). The issue of learning spaces was considered to be in an area where there is a lack of current data and so qualitative data is used to demonstrate both the importance of learning spaces to employees and the types of spaces that are identified as making a difference.

The paper is based upon empirical data gathered from three case studies of hotel schools which were considering how knowledge is created and what were some of the barriers or facilitators affecting learning and knowledge creation. The three cases were chosen as, although the organisations were similar in their size and product, they had very different contexts and relationships (especially between employees and managers) and so the mental attitudes towards learning and knowledge creation might, potentially, be different. The employees attitudes towards the organisation ranged from very good, through average to extremely negative in the third. The employee attitudes were established through metaphor analysis whereby respondents were asked to give metaphors that described their feelings towards their organisations at the time of the interview. These were then compared and an overall picture of the state of the context and relationships for organisation was established (Schmitt, 2005). From this it was established that one organisation had a very positive relationship between management employees, one had a poor relationship and one was average. 
The qualitative studies were undertaken using in-depth semi-structured interviews and focus groups from a variety of stakeholders within and around the hospitality industry. These methods were used to explore the relationship between the employee and employer attitudes, potential stickiness and effective knowledge management within these organisations.

14 focus groups were held that involved 45 people in total (this represents $40 \%$ of the total staff involved in the three case study locations). 15 interviews, which lasted about 30 to 45 minutes each, were undertaken which reflected the same population as the focus groups. Similar questions were asked in each data collection method and a comparison was made early on before all the data had been collected, in order to establish whether a similar pattern of data was emerging in each mode of collection. As this proved to be the case, it was not considered necessary to interview all the respondents but to continue to develop focus group responses. The data was entered into NVIVO and coded, enabling an analysis using axial and thematic coding to be used (Pandit, 1996). This coding allowed themes to emerge which permitted a range of issues to be explored. In this paper the themes that will be highlighted are those that relate to the role of space in the enhancement or limitation of knowledge creation and transfer.

\section{Findings}

From the data a range of examples of the different spaces emerged (figure 2) as being where learning and knowledge creation occurred. These were not really a surprise but it was important to reflect the participants' views.

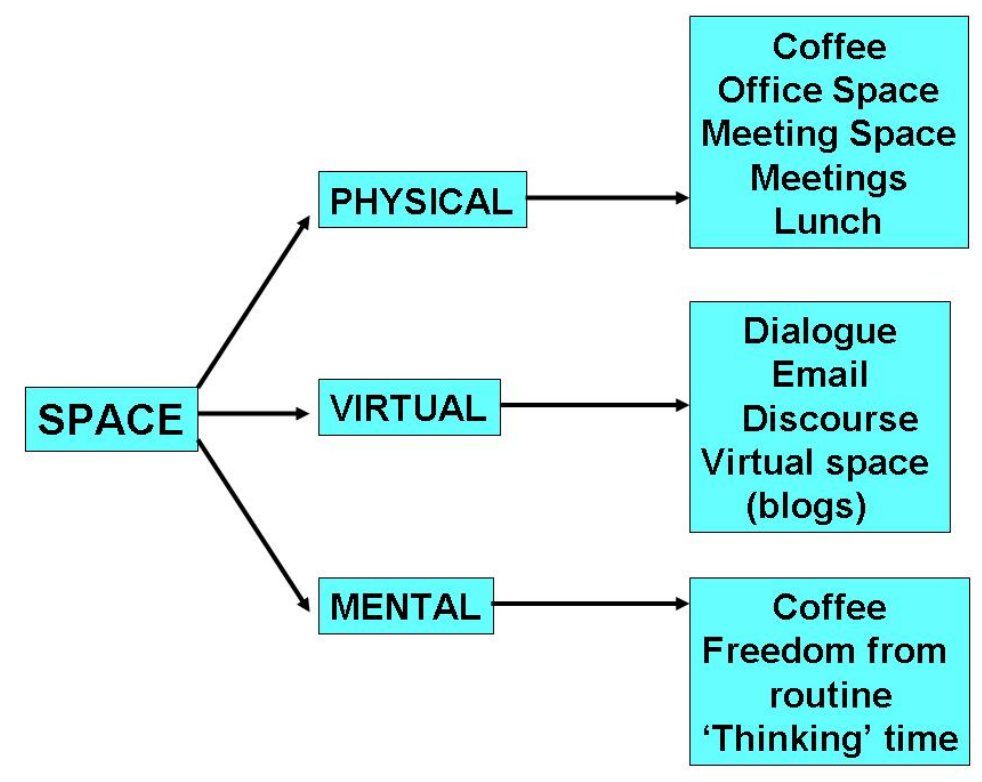

\section{Figure 2: Forms of Space}

What was of more interest was that the provision of space was not enough. This was particularly the case for virtual space which was rarely offered as a sole source of useful or effective space, thereby confirming the work of McPherson and Nunes (2004). What also became clear was that space affected, and was affected by, stickiness. The themes that emerged were that actors, context and space all led to an increase or decrease in knowledge stickiness. The importance of the relationships can be shown in figure 3 where different stickiness predictors can be seen to be overcome or not in different contexts. This table merely shows examples of the relationships found but gives a clear picture of the causality that emerged.

An unexpected, but recurring, concept within the data was that of "coffee". The coffee premise emerged through both thematic and axial coding as an indication of potential learning spaces. Stories were disclosed where coffee enabled learning, but also of where "coffee rights" had 
been removed by managers who felt that the informal spaces were a challenge to their power, with a consequent challenge to relationships and a reduction in knowledge transfer.

\begin{tabular}{|c|c|c|c|}
\hline Knowledge & Space & $\begin{array}{c}\text { Stickiness } \\
\text { Barrier }\end{array}$ & Outcome \\
\hline $\begin{array}{l}\text { Held by } \\
\text { employees }\end{array}$ & Coffee & $\begin{array}{c}\text { Capacity to retain } \\
\text { is high }\end{array}$ & $\begin{array}{l}\text { Knowledge } \\
\text { Retained }\end{array}$ \\
\hline $\begin{array}{l}\text { Held by } \\
\text { employees }\end{array}$ & $\begin{array}{c}\text { Office/ } \\
\text { Formal Meetings }\end{array}$ & $\begin{array}{c}\text { Lack of } \\
\text { motivation } \\
\text { (disinterested } \\
\text { senior } \\
\text { management) }\end{array}$ & Knowledge Lost \\
\hline $\begin{array}{l}\text { Held by senior } \\
\text { management }\end{array}$ & $\begin{array}{c}\text { Office/ } \\
\text { Formal Meetings }\end{array}$ & $\begin{array}{c}\text { Clarity of } \\
\text { importance to } \\
\text { both the } \\
\text { organisation and } \\
\text { staff }\end{array}$ & $\begin{array}{l}\text { Knowledge } \\
\text { Retained and } \\
\text { Used }\end{array}$ \\
\hline $\begin{array}{l}\text { Held by senior } \\
\text { management }\end{array}$ & Coffee & $\begin{array}{c}\text { Sources are seen } \\
\text { as 'gossips' and } \\
\text { not reliable }\end{array}$ & Knowledge Lost \\
\hline
\end{tabular}

Figure 3: Examples of potential outcomes between actors, context and stickiness predictors

The core implication from the outcomes outlined was that the relationships and the proximity were extremely important. Not surprisingly there tends to be more sharing and growth with those people you spend time with, however there must be a propensity to share and the interactions within a space were a way of developing the relationship into one that would enable sharing. The paper will now look at each of the three types of spaces and consider how the actors, context and knowledge present are affecting and affected by knowledge stickiness.

\section{Physical Space}

Coffee as a metaphor for physical space was a need and issue that raised itself out of the data: "Because over coffee....yeah over the coffee! \{You ask and find out\} How would you do that...or why don't you try doing it this way"; "It's quite incredible how much work happens...Everybody meets... Everybody has coffee...There's the stuff that you planned and the stuff that you hadn't and it's just so important". The informal spaces created had an effect on actors (recipients) motivation or passivity, communication channels and messages (Rodgers, 1983:145-148).

Restrictions on physical spaces for coffee areas which are used as a thinking space, such as staff rooms reduce the opportunity for discussion and transfer of knowledge. On staff it had the effect of questioning the system and why there was no space for the actors: "yeah, like having a staff room has been a huge issue here ...it's their [management] decision not to have one - That's consistent across all of the [properties in the corporate group of six]. I find it intriguing. Yeah, none of sites does have them [staff rooms] have you? ....Not to have a staff room, what do you think that means?"; "By law with a certain amount of staff you must have a staff room... a communal, eating, rest spot"; "Its funny it's like.... we are paying for an education and for our food and accommodation. We have to take our coffee [laughter] only when we are offered one, which does annoy me. The first year students have to learn coffee making, and if you want a coffee at lunchtime, half time you're not allowed one". 
The reduction in places and spaces appears to have resulted in actors creating spaces, physical spaces listed for other purposes were taken over and turned into 'coffee or lunch' spaces, enabling sub groups, work groups or cliques to meet and seek out informal knowledge sharing and transfer rather then formal information sources. Resulting in the potential to be passive to new knowledge, out rightly reject formal knowledge, plan hidden sabotage or foot dragging on change (Hayes \& Clarke,1985). "But we do have facilities - it's not called a staff room - but we use it as a staff room if we need to. We have a small student tutorial room that seats about six. It's like a little round table and if it's cold we'll eat in there". "Verses the rest of us go to student dining and eat there... with no real space for discussion". [A collective sigh transpires] "Like sitting here today, it is so nice, like a breath of fresh air for me - 'oh, let's talk to someone different'! It is almost like a bit of time out. I actually felt ... I have an excuse to actually talk about something not just around work".

The reduction of physical spaces limits the actors' ability to verbalise their ideas in the broader community context due to being in earshot of students: "Yeah, because you go for lunch and there are students serving...you cannot say what you mean ... you have conversations but you have to be careful. You might want to discuss an issue with someone at lunch or something...but cannot...or if you are in a shared office and you want to talk about something confidential. You cannot. I find it interesting because I have gone to a university that it did not happen in...in addition, it is just so important. There is so much work [knowledge transfer] that happens in that staff room... Yeah, absolutely!"

The data unearthed a strong need for space and the freedom to think, discuss and reflect on ideas. Consequently, actors went to the extent to put themselves at risk their health was concerned to find appropriate spaces: "When I was in the UK, I visited the smoking room....that's the best place, and I don't smoke...I opened the door and they are all sitting in their laughing and ...being wicked, yeah! And sometimes we had meetings in there...but it just, lots of knowledge sharing".

Locations of offices were also seen as important by actors for the transfer of knowledge: " I think it is important." It's really is to do with geography" the office location and how far it is from others in the work group. Secondly, the immediate need of the actor to find the space and have the conversation. "I spend a lot of my time with [person] in HR re the staff development... we're both in separate offices. Therefore, we catch up at lunchtime and have a chat and have coffee....and Nita's down there...she's kind of acting line manager, so - yeah, I'll have a discussion with her or morning tea down in her office."

Actors also discussed concepts of individuality and personality, "some days the way you feel relates to the way you work. It is more about personality... some people you know like to keep to them and form their ideas in their heads. Once they really think its finished or more developed then they put it out there... but they still need space", underpinning the need for personal workspace as well as group workspace pending on the individuals ability to generate new ideas of transfer knowledge intrinsically in their own mental space: "Personally I probably learn more knowledge and information...subconsciously...in my own time...because it's just the way that you do something".

\section{Mental Space}

The following data reveals that the actors, context and current knowledge levels are linked; and are enacted simultaneously whilst they connect the physical and or virtual and mental spaces we seek that facilitate transfer and reduce stickiness. Listening or listening channels and the quantity and complexity of information also had implication for knowledge transfer. Actors discussed the need for both physical and mental space to reduce their lack of knowledge, and as such stickiness, and increase the transfer of knowledge.

Some recipients discussed their lack retentive capacity, a "lot of listening went on... across to [to] one another, in the same room, so I was able to take a lot of information in...but again its really my ability to think out that information... and how much I needed to get through.....and now its an understanding of how much more I need to research to step up to the next level". 
Other participants argued the complexity and magnitude of the workload led to a focus on getting things done and that there was not enough space to enable novelty, new ideas or "a new lease of life"; "It would be wonderful to have enough space to think". Actors also displayed concerns for the expectations of efficiency by management: "A lot of this is about work pressure on time and space". Management do not appear to realise the need for space in order for individuals and groups to create new ideas and reduce stickiness of knowledge: "Because there's not the time... not enough physical time and mental space...I would like to spend more time on this but it seems that all the time is taken up with trouble shooting/problem solving, lecturers coming to us with their problems, you know, about a student or a classroom or an incident of plagiarism or something like that. So all your time is taken up with those kinds of things and you don't have all of space for the creation of new ideas". "Yeah, I think so, its not having the space to think about it". From the actors perspectives, management seems too short term focussed to allow people their space: "that some issues are too big to work on when there are all these little things that have to be done today or tomorrow. I kind of feel a little bit guilty spending time looking at something for the future when there's all these things now that need to be dealt with. Nothing ever gets looked at for the future". Concepts of high workload and little space can lead to the concept of 'busyness' and use of routine patterns and procedures that reduce cognitive overload and create spaces for new information to be used as an excuse for the mind not to transfer and share knowledge and increase stickiness whilst limiting innovation and new ideas.

The provision of physical space and the relationships and knowledge transfer this creates, can be arduous or easy: "Each group will meet and we might look and review our actions and then we work through what we said last time and that kind of generates discussion...the face to face is making all the difference for you? Yeah! Moreover, that process is forcing the face to face to happen. So it's giving you the space to do it"; "The focus is so much on the students, in all three institutions it is the same, that there is no breathing space in there in any other time than when the students are gone in week 20 and here we've got a week to get everything ready and there is no breathing space".

Not only is space not enough if there is a shortage of time, where the recipient is not perceived as reliable or important enough to be informed. (Szulanski: 1999) there will also be knowledge transfer reduction: "In this organisation there is a lot of that that goes on, where people are in certain positions and if they are given opportunity to be allowed access to the information about certain situations they could create new knowledge". "I mean particularly in our department we have to be very careful of what we disclose". "So there is a restriction on information being shared about to everybody on an equal level, on an equal basis"

Stickiness in the mental space can also be influenced by how others use power. If participants do not feel safe to share knowledge and use the symbol of coffee as an indicator of perceived inequality and why the space was not one where they could communicate their needs and give feedback. Consequently, no new knowledge was being created. The use of individual and organisational manipulation and poor use of power has a strong impact in the reduction of spaces for knowledge transfer and diminishes innovative ideas has a negative impact on stickiness and increases it further. Power in creating the space 'over coffee' appears to be a contextual issue for all three organisations as reflected in the data: "I think they all have more clout, so they can probably get coffee when they want to. I am sure there is a third year student sitting at a table who would be sure to get coffee. I think with a first year, 'any chance I could get a cup' no you can't have a coffee today.... that's the law of the jungle, nothing wrong with it in my opinion, that's life... but I don't think...there's...if coffees are being offered, they're offered to everyone"... its the pecking order, its an issue of power".

A lack of reciprocity also reduced learning where there appeared to be no mutual exchange of privileges, no specific reward or recognition for additional work, company or customer loyalty or validity for the experiences or knowledge of the staff. On the surface, making staff disgruntled at such a small and petty thing as coffee, in reality this is a much more complex and sophisticated issue in the process of organisational learning and within the learning action itself: "We all know we could be getting lecturing jobs somewhere else, do pay more, but we are here because we want to be."; "You give it your all....but then there comes some sort of collapse that happens... and like l'd have to say this happened earlier this semester, 
there it was, just simple [motivation gone, management] make little stupid mistakes; things like coffee. To get a coffee is a major bonus, we can't have a cup of coffee here, because were not allowed to"; "Now then we can't get a coffee but management don't mind us working all over the weekend, You think what I am doing....we are not allowed to have coffee....we are told that....so again not a lot of loyalty.....going around, no reciprocal arrangements".

One of the effects that impacts on and restrict knowledge transfer is who considered appropriate to receive new information. Even if there is space there is nothing to share in that space, but what can happen is that informal sharing enables knowledge creation that is not possible within the formal organisational structure. The sources of knowledge from people in the organisation are paramount in the actor channelling and receiving knowledge. Given the revelations in the data, trust of the source seems vital. Management is seems could have an credibility issue in terms of actors in the extreme allowing formal information in or more subtly feigned acceptance of data from formal sources. Where as more informal sources from informal spaces to the sharing of expert knowledge appear to have additional credibility and are valued more" and management see the knowledge of academics as unproven knowledge.

The concept of the organisational cultural providing mental space as a sanctuary, a space to rest and be sheltered from the tornado of change, reflects the notion of the organisation being 'fertile' and a space for growth even though enormous amounts of changes were to being undertaken: "Just before the transition from public to private institution and I guess going on the use of a metaphor, it was like a bit of tornado...which is on the surface of things. Like we're all doing these changes...rushing around doing all these things, but throughout it all I can see its good, because we've managed to keep the same culture in the place. Culturally, everyone wants everyone to talk really personal, everyone gets along great and its innate...so on the inside its pretty calm... although there's all these things happening around you, like you feel like everything is still OK...you can sort of deal with this changes. Yeah...and...so it would feel like the 'eye of a storm' you in a calm space".

Some actors created their own barriers to knowledge transfer and sharing: "I've noticed it at all sorts of functions, our Christmas function, I go and deliberately sit elsewhere, but that's just me. The kitchen staff will draw their own lines and be comfortable in their own sub culture, because a lot of the times management try to mix us up. Still if house keeping staff came in here and made themselves a cup of coffee, nobody is going to say 'no' to her, 'you're not allowed to do that". Other forms of barriers exposed reflect the impact of the concept that one has of oneself. Theories of causal ambiguity or expectancy theory, the given actions will result in the given outcomes seem to reflect some cub cultures need for stability not transfer: "Housekeeping have a coffee machine down in the main foyer to share, but they never used it, they wanted a tin of instant Nescafe instead, well that's probably the way they saw themselves, or they would choose to be.....too much trouble to go and get coffee as they would have to share and it takes them out of their comfort zone... people would complain bitterly about how they're not treated equally but whenever they've given the opportunity, no, we are just the......housekeeping, the maintenance, but whatever, they're actually strength and comfort by being in their own little pockets, quite happy, when given the opportunity, or whatever that word is to complain, that they're not treated equally". This leads to suggestions of a barren organisational culture where sub-cultures create their own community to support them in their learning, transfer and comfort in specific range of technical ideas.

Evidence of the importance of such sub groups showed: "I believe there have been some cutbacks in terms of finance recently, in terms of amount of coffee has been drunk...something I think....some people I think have been told to be a little more judicious about, but I haven't seen a written directive or been given it myself.. I don't.....think its an organisation in the world, right where it doesn't happen, hospital, university, ... whatever, but people put themselves out and their hands in their pockets to buy their own coffee machine or water cooler". This demonstrates both a challenge to the power given through fiscal authority and the cultural need for coffee as a space to share, discuss and clarify or reduce the stickiness of knowledge, information or data.

\section{Virtual Space}


Virtual places were not well represented amongst the space discussed by the actors in the three case studies, although they had been raised as places to think and share knowledge. Organisational learning and knowledge transfer literature identifies strong potential and power for the future or electronic spaces as alternative spaces for knowledge transfer, however the reality is still a long way behind. Environments or contexts described by participants reflected the need for face to face information exchanges, sharing enabling stronger knowledge transfer. E-mails were the major virtual source of space discussed; actors felt that e-mail had the most potential for daily use. Actors noted the opportunity for use of real time blogs and other virtual tools, such as web sites, intranet or internal knowledge based sites and shared web spaces from information technology providers such as G-mail, Hotmail and Yahoo mail and similar portals. Similarly, global organisations recognise and utilise virtual spaces as a means to communicate and share corporate knowledge.

Given the characteristics of the hospitality and education industries studied in the three case studies and the generic nature of the practitioners, trainers and lecturers, possible reasons for this limited use of virtual spaces are low location or geographic challenges and the concept that the majority of actors in these areas of work major leaning and teaching style is experiential and observational. They require a face to face interaction both on the hotel floor and in the classroom, limiting the use of virtual spaces without major paradigm shift in change.

\section{Implications}

In many ways this paper supports many writings about the need for space, trust, face-to-face interactions etc. What is different, however, is the relationship between such spaces and the potential to develop or overcome knowledge stickiness. What becomes clear is the need to actively manage the creation and support of all three forms of space. It is also important to actually think about what is a space and how it can be nurtured. There also needs to be a consideration as to whether it is the actual location of a space that matters such as the staff room existing, or whether it is the gap between other things in terms of time to think and consider other issues.

We suggest a reconfiguring of Figure 3 to encourage a managing of the spaces in a way so as to actively think about what the forms of stickiness may be and how they can be overcome via the provision of appropriate space as well as the forms of support that will need to go with this.

\begin{tabular}{|c|c|c|c|c|}
\hline Knowledge & $\begin{array}{c}\text { Potential } \\
\text { Stickiness } \\
\text { Barrier }\end{array}$ & $\begin{array}{c}\text { Space } \\
\text { type } \\
\text { needed }\end{array}$ & $\begin{array}{c}\text { Support } \\
\text { Required }\end{array}$ & Outcome \\
\hline $\begin{array}{c}\text { Held by } \\
\text { employees }\end{array}$ & $\begin{array}{c}\text { Capacity to } \\
\text { retain }\end{array}$ & $\begin{array}{c}\text { Physical } \\
\text { Informal }\end{array}$ & $\begin{array}{c}\text { Coffee } \\
\text { Time } \\
\text { Ability to implement } \\
\text { ideas }\end{array}$ & $\begin{array}{c}\text { Knowledge } \\
\text { Retained }\end{array}$ \\
\hline $\begin{array}{c}\text { Held by } \\
\text { employees }\end{array}$ & $\begin{array}{c}\text { Lack of } \\
\text { motivation (on } \\
\text { either } \\
\text { side)/Arduous } \\
\text { relationship }\end{array}$ & $\begin{array}{c}\text { Physical } \\
\text { Formal } \\
\text { Virtual }\end{array}$ & $\begin{array}{c}\text { Time spent developing a } \\
\text { shared understanding of } \\
\text { why the meetings and } \\
\text { sharing are of } \\
\text { importance to each other }\end{array}$ & $\begin{array}{c}\text { Knowledge } \\
\text { Retained }\end{array}$ \\
\hline $\begin{array}{c}\text { Held by Senior } \\
\text { Management }\end{array}$ & $\begin{array}{c}\text { Sources are } \\
\text { not reliable }\end{array}$ & $\begin{array}{c}\text { Physical } \\
\text { Formal } \\
\text { Informal }\end{array}$ & $\begin{array}{c}\text { Coffee } \\
\text { Time spent developing } \\
\text { stories of the success of } \\
\text { knowledge utilised by } \\
\text { others before }\end{array}$ & $\begin{array}{c}\text { Knowledge } \\
\text { retained }\end{array}$ \\
\hline $\begin{array}{c}\text { Held by } \\
\text { employees }\end{array}$ & $\begin{array}{c}\text { Causal } \\
\text { ambiguity }\end{array}$ & $\begin{array}{c}\text { Mental } \\
\text { Formal }\end{array}$ & $\begin{array}{c}\text { Time to think and } \\
\text { experiment }\end{array}$ & $\begin{array}{c}\text { Knowledge } \\
\text { developed } \\
\text { and retained }\end{array}$ \\
\hline
\end{tabular}

Figure 4: Managing Spaces to Overcome Stickiness 
In many ways this seems simple and yet it is a conversation that few organisations currently engage in. The role of the space is crucial as well as its form and the way that it is perceived by those involved in learning and knowledge creation. Many of the spaces could and should be self-organising, as was demonstrated with the focus upon coffee. However, the support that this needs should be recognised and supported. Of particular value form the data was the recognition as to the ease with which networks and structures can be ruptured, affecting all aspects of the context and relationships, thereby preventing knowledge transfer.

\section{Conclusion}

In this paper we have identified possible roles of space in terms of its role in enabling organisational learning and knowledge creation. We have also identified how managing space may enable knowledge stickiness predictors to be overcome. The very important role of informal space, as seen through the story of 'Coffee' enabled an analysis of how space alone is not enough - there need to be specific forms of support which enable the space to be effectively utilised. We argue that organisations need to actively discuss the spaces and the support they provide in order to increase organisational learning. 


\section{References}

Argyris, C. and Schon, D.A. (1996). Organizational Learning II : Theory, Method and Practice. Masachusettes, USA: Addison-Wesley.

Carlile, P.R. and Rebentisch, E.S. (2003). 'Into the Black Box: The Knowledge Transformation Cycle.' Management Science, 49 (9): 1180-1195.

Cook, S.D.N. and Brown, J.S., (1999). 'Bridging Epistemologies: The Generative Dance Between Organizational Knowledge and Organizational Knowing.' Organization Science, 10, 4 (July-August): 381-400.

BrainyMedia (2008). 'Space'. www.brainyquote.com/words/sp/space221985.html.

Creswell J.W. (1994). Research design, qualitative and quantitative approaches. London: Routledge.

Creswell, J. W. (2003). Qualitative, quantitative, and mixed methods approaches. London, Sage.

Easterby-Smith, M. (1997). 'Disciplines of Organizational Learning: Contributions and Critiques'. Human Relations, 50 (9): 1085-1113.

Easterby-Smith, M., Snell, R. and Gheradi, S. (1998). 'Organizational Learning: Diverging Communities of Practice'. Management Learning, 29 (3): 259-272.

Edenius, M. and Yakhlef, A. (2007). 'Space, Vision and Organisational Learning'. Management Learning, 38 (2): 193-210.

Elkjaer, B., (1999). 'In Search of a Social Learning Theory'. In Easterby-Smith, M., Burgoyne, J. and Araujo, L., (Eds.) (1999). Organizational Learning and the Learning Organization. London: Sage.

Firestone, J. M. and McElroy, M. W. (2004). 'Organizational Learning and Knowledge Management: The Relationship', The Learning Organisation, 11 (2): 177-184.

Guldberg, K. and Pilkington, R. (2006). 'A community of practice approach to the development of non-traditional learners through networked learning.' Journal of Computer Assisted Learning, 22: 159-171.

Hayes, R.H. \& Clark, K.B. 1985 Exploring the Sources of Productivity Differences at the Factory Floor Level. NY: Wiley.

Hutchinson, C.B. (2006) 'Cultural constructivism: the confluence of cognition, knowledge creation, multiculturalism, and teaching.' Intercultural Education, 17 (3): 301-310

Jensen, R. and Szulanski, G. (2004). 'Stickiness and the adaptation of organizational practices in cross-border knowledge transfers.' Journal of International Business Studies, 35 (6): 508-523.

Kets de Vries, M.F.R. and Korotov, K. (2007). 'Creating Transformational Executive Education Programs'. Academy of Management Learning and Education, 6 (3): 375-387.

Leedy, P.D and Ormrod, J.E. (2005) Practical Research: Planning and Design. 8th Edition. Upper Saddle River, NY: Merril Prentice Hall.

McElroy, M.W. (2000). 'Integrating complexity theory, knowledge management and organizational learning'. Journal of Knowledge Management, 4 (3): 195-203

McElroy, M.W. (1999). 'Double-Loop Knowledge Management'. IBM Knowledge Management Consulting Practice, August, www.learning-org.com/docs/cElroyDLKMv3.pdf. 
McPherson, M. and Nunes, M.B. (2004). 'The failure of a virtual spcial space (VSS) designed to create a learning community: lessons learned.' British Journal of Educational Technology, 35 (3): 305-321.

Newell, S., Robertson, M., Scarborough, H. and Swan, J. (2002). Managing Knowledge Work. Basingstoke: Palgrave.

Nonaka, I. and Konno, N. (1998). 'The concept of "ba": Building a foundation for knowledge creation'. California Management Review, 40 (3): 40-54.

Pandit, N.R. (1996). 'The Creation of Theory: A Recent Application of the Grounded Theory Method's The Qualitative Report, 2 (4): http://www.nova.edu/ssss/QR/QR2-4/pandit.html.

Prange, C. (1999). 'Organizational Learning - Desperately seeking a theory?'. In EasterbySmith, M., Burgoyne, J. Araujo, L. (eds.), Organizational Learning and the Learning Organization: developments in theory and practice. London: Sage.

Robbins, S.P. (2000). Essentials of organizational behaviour. 6th edition, Upper Saddle River, $\mathrm{NJ}$ : Prentice Hall.

Rogers, E.M. 1983, The Diffusion of Innovation. New York: Free Press.

Roth, A.V., Marucheck, A.S. Kemp, A. and Trimble, D. (1994). 'Knowledge factory for accelerated learning processes'. Planning Review, 22 (3): 26-33.

Schmitt, R. (2005). Systematic Metaphor Analysis as a Method of Qualitative Research'. The Qualitative Report, 10 (2): 358-394 http://www.nova.edu/ssss/QR/QR10-2/schmitt.pdf.

Soloman, N., Boud, D. and Rooney, D. (2006). 'The in-between: exposing everyday learning at work'. International Journal of Lifelong Education, 25 (1): 3-13.

Strauss, A. and J. M. Corbin (1998). Basics of Qualitative Research - Techniques and Procedures for Developing Grounded Theory. London, Sage.

Szulanski, G. (2000). 'The Process of Knowledge Transfer: a diachronic analysis of stickiness'. Organizational Behavior and Human Decision Processes, 82 (1): 9-27.

Szulanski, G. (1995). 'Unpacking Stickiness: an empirical investigation of the barriers to transfer best practice inside the firm.' Academy of Management Proceedings, 437-441.

Tsoukas, H. and Vladimirou, E. (2001). 'What Is Organisational Knowledge?', Journal of Management Studies, 38 (7): 973-993.

von Hippel, E. (1004). "'Sticky information" and the Locus of Problem Solving: implications for innovation.' Management Science, 40 (4): 429-439. 